\title{
Sugar composition and in vitro glycaemic response of selected sugars, rice-based meals and traditional kuih
}

\author{
${ }^{1}$ Mohamad Nawawi, F.N., ${ }^{1}$ Ahmad Fadzly, I.S., ${ }^{1}$ Noor Safiqah Ain Safingi, N.S.A., \\ ${ }^{4}$ Mustafa Khalid, N., ${ }^{4}$ Md Noh, M.F. and ${ }^{1,2,3 *}$ Azlan, A. \\ ${ }^{1}$ Department of Nutrition and Dietetics, Faculty of Medicine and Health Sciences, University Putra \\ Malaysia, Selangor, Malaysia \\ ${ }^{2}$ Research Centre of Excellence for Nutrition and Non-Communicable Diseases, Faculty of Medicine and \\ Health Sciences, Universiti Putra Malaysia, UPM Serdang, 43400 Selangor, Malaysia. \\ ${ }^{3}$ Halal Products Research Institute, Universiti Putra Malaysia, 43400 UPM Serdang, Selangor \\ ${ }^{4}$ Nutrition, Metabolism and Cardiovascular Research Centre, Institute for Medical Research, National \\ Institutes of Health Complex, Level 3, Block C6, No 1 Jalan Setia Murni U13/52 Seksyen U13 Setia Alam \\ 40170 Shah Alam Selangor
}

\begin{abstract}
Article history:
Received: 13 August 2019 Received in revised form: 7 December 2019

Accepted: 23 December 2019

Available Online: 10

February 2020
\end{abstract}

\section{Keywords:}

Sugar composition,

Glycaemic response,

Sugars,

Traditional kuih,

Rice dishes

\section{DOI:}

https://doi.org/10.26656/fr.2017.4(S1).S08

\begin{abstract}
High glycaemic index foods were found to increase the risk of getting diabetes, obesity, cancer and cardiovascular disease. This study aimed to determine the in vitro glycaemic response and sugar composition of selected food types, which include sugars, rice-based meals and traditional cakes and desserts (kuih). The food samples were purchased prepared and analysed using High Performance Liquid Chromatography (HPLC) to determine the sugar composition. The samples were also prepared and assayed using validated in vitro digestion method to determine the estimated glycaemic response. The in vitro method used $0.25 \mathrm{~g}$ total available carbohydrate, which was established by Clegg Anthrone method. Among the studied samples, the total sugar content was icing sugar (100\%), which has the highest percentage, nasi kerabu (7.49\%) and kuih lapis $(42.20 \%)$ for sugars, rice-based meals and traditional kuih, respectively. Dialyzable glucose concentration for the sugar samples was highest in the sugar in sachet $(3.47 \mathrm{mg} / \mathrm{mL})$ and lowest in the sugar with stevia $(0.49 \mathrm{mg} / \mathrm{mL})$. For the different types of rice-based meals, the highest dialyzable glucose concentration was in nasi lemak $(13.06 \mathrm{mg} / \mathrm{mL})$, and the lowest was in nasi kerabu $(12.33 \mathrm{mg} / \mathrm{mL})$. While for traditional kuih, kuih lapis (10.53 $\mathrm{mg} / \mathrm{mL})$ and kuih keria $(6.30 \mathrm{mg} / \mathrm{mL})$ were highest and lowest in the dialyzable glucose concentration, respectively. Significant correlations exist between dialyzable glucose concentration (at 120 minutes) and sugar composition $(\mathrm{p}<0.05)$ for the rice-based samples. Among the traditional kuih samples, sucrose content and total sugar content was correlated significantly. However, no correlation exists between dialyzable glucose concentration and sugar composition for the selected sugar samples. Factors such as particle size and presence of phytochemical in sugars, available nutrients (starch, protein and fat) in kuih and cooked dishes as well as the amount of added sugar in food are vital factors that affect the in vitro glycaemic response of the studied samples.
\end{abstract}

\section{Introduction}

According to Malaysian Adults Nutrition Survey, MANS $(2003 ; 2014)$ traditional cake and desserts or kuih are the top 10 daily consumed foods among the different ethnics in Malaysia. While cooked rice is commonly consumed during lunch and dinner with an average intake of white rice at 2.5 plates per day (Norimah et al., 2008). Malaysians usually consume cooked rice with vegetables and fish or chicken (Nur Indrawaty et al.,
2012). Nasi lemak is one of the famous rice-based breakfasts in Malaysia while traditional kuih are consumed during breakfast or evening tea (high-tea) as snacks.

During preparation, rice-based meals are often added with fat (such as oil, coconut milk, margarine or butter), protein (such as egg, meat or chicken) and sugars to enhance the palatability of the cooked meals. Traditional kuih preparation also commonly uses different types of 
sugar to suit the final taste and texture. Quite recently, a study reported that among the top 10 food items contributed to the intake of added sugar $(8.1 \%$ of added sugar) of Klang Valley population was the commercial and traditional snacks (Sharifah Azizah et al., 2015). The consumption of different sugars as a sweetener in most snacks and traditional kuih can raise the blood sugar levels at different rates. Besides sugar, the available carbohydrate in traditional kuih and rice-based meals also contributes to the source of sugar.

Sugars defined as carbohydrates, which supply energy for the body in the form of glucose present as a significant part in a food product by imparting the sweetness and the function of sugar. The daily sugar intake among Malaysian was at approximately $37 \mathrm{~g}$ (Amarra et al., 2016). The WHO recommends sugar intake should be below $50 \mathrm{~g}$ per day in order to decrease the risk of chronic diseases (WHO, 2015).

Food with high granulated sugar content has high glycaemic index (GI) value (Chong et al., 2019). The GI is calculated as the measured glycaemic response to a portion of test food containing a specific portion of available carbohydrate (usually $50 \mathrm{~g}$ ) expressed as a percentage of the glycaemic response to the same amount of available carbohydrate from a reference food eaten by the same subject (Englyst et al., 1999; Jenkin, 2007). Glycaemic response is the post-prandial blood glucose response (change in concentration) elicited when a portion of food or meal that contains carbohydrate is ingested. While the glycaemic index (GI) is a system that classifies carbohydrate-containing foods according to how fast they are digested and absorbed during the postprandial period (Almousa et al., 2013). The glycaemic response can be estimated by measuring the GI and glycaemic load (GL) using in vitro or in vivo methods (Argyri et al., 2016).

The presence of protein and fat could reduce the glycaemic responses by $25 \%$ to $39 \%$ (Sun et al., 2014). Some of the traditional kuih may cause high glycemic response due to the uses of refined sugar in their preparation, but rice-based mixed meals have been shown to cause a significantly lower incremental peak of glucose when compared to cooked white rice alone (Sun et al., 2014).

The consumption of high glycaemic food could increase the risk of development of non-communicable diseases such as diabetes, hypertension, cardiovascular diseases and certain cancers. According to Augustin et al. (2015), it is significant to develop a list of glycaemic index values of foods for health professionals and the public to use as a diet guide. Therefore, the aim of this study was to determine the in vitro glycaemic response and the sugar composition of selected traditional kuih (sugared donut, kuih keria, pau rendang ayam, kuih lapis, kuih cara and kuih kemboja), selected rice-based meals (nasi kerabu, chicken porridge, fried rice and nasi lemak), and selected sugars (refined sugar, aromatic brown sugar, soft brown sugar, minimal refined brown sugar, icing sugar, sugar with stevia, sugar in sachet and gula melaka) in Malaysia. In vitro method was selected as it offers as an alternative method to the in vivo method. The in-vitro method predicts the glycaemic index response more rapidly, at a lower cost, need minimal skills and infrastructures, and allows multiple samples of food in simultaneous testing (Argyri et al., 2016).

\section{Material and methods}

\subsection{Chemicals and reagents}

Diluted sulphuric acid $\left(\mathrm{H}_{2} \mathrm{SO}_{4}\right)$ (sulphuric acid: water, 2.3:1.0, v/v), 52\% perchloric acid $\left(\mathrm{HClO}_{4}\right)$ (mixture of $270 \mathrm{~mL}$ of perchloric acid (sp gr 1.70) and $100 \mathrm{~mL}$ of water, RandM Chemical), Anthrone reagent (Friendemann Schmidt, AR grade), glucose standard (food grade) stock solution (mixture of $100 \mathrm{mg}$ of glucose and $100 \mathrm{~mL}$ distilled water), glucose standard working solution (10 mL of glucose standard stock solution diluted with water to $100 \mathrm{~mL}$ volume), $0.1 \mathrm{M}$ hydrochloric acid ( $\mathrm{HCl})$ solution, piperazine-N,N'-bis(2ethanesulfonic acid) (PIPES) buffer (0.5M, pH 6.5, 100 $\mathrm{mL}$, Solarbio), pancreatin from porcine pancreas ( $4 \mathrm{X}$ cell culture, Sigma-Aldrich), bile salts (Solarbio), 3, 5Dinitrosalicylic acid, pepsin from porcine gastric mucosa powder $500 \mathrm{U} / \mathrm{mg}$, Sigma Aldrich) amyloglucosidase (powder form, Solarbio), and ethanol (John Kollin Chemical).

\subsection{Preparation of samples}

Four rice-based meals were fried rice, nasi kerabu, nasi lemak and chicken porridge; six traditional kuih was sugared doughnut, kuih keria, pau kaya, kuih lapis, kuih cara and kuih kemboja were purchased from food stalls and restaurants around Serdang, Selangor while seven types of sugar (refined sugar, aromatic brown sugar, soft brown sugar, minimal refined brown sugar, icing sugar, sugar with stevia, sugar in sachet and gula melaka) were gift from Central Sugar Refinery Sdn Bhd, Malaysia (Figure 1) for the study. White rice, glucose, and white bread were used as the reference food. All the foods were purchased from Sri Serdang area. Each of the samples was ground together to homogenize, followed by freeze-drying before the experiment. The freeze-dried samples were blended into powder form and kept in an airtight container and stored in the refrigerator at $4{ }^{\circ} \mathrm{C}$. 


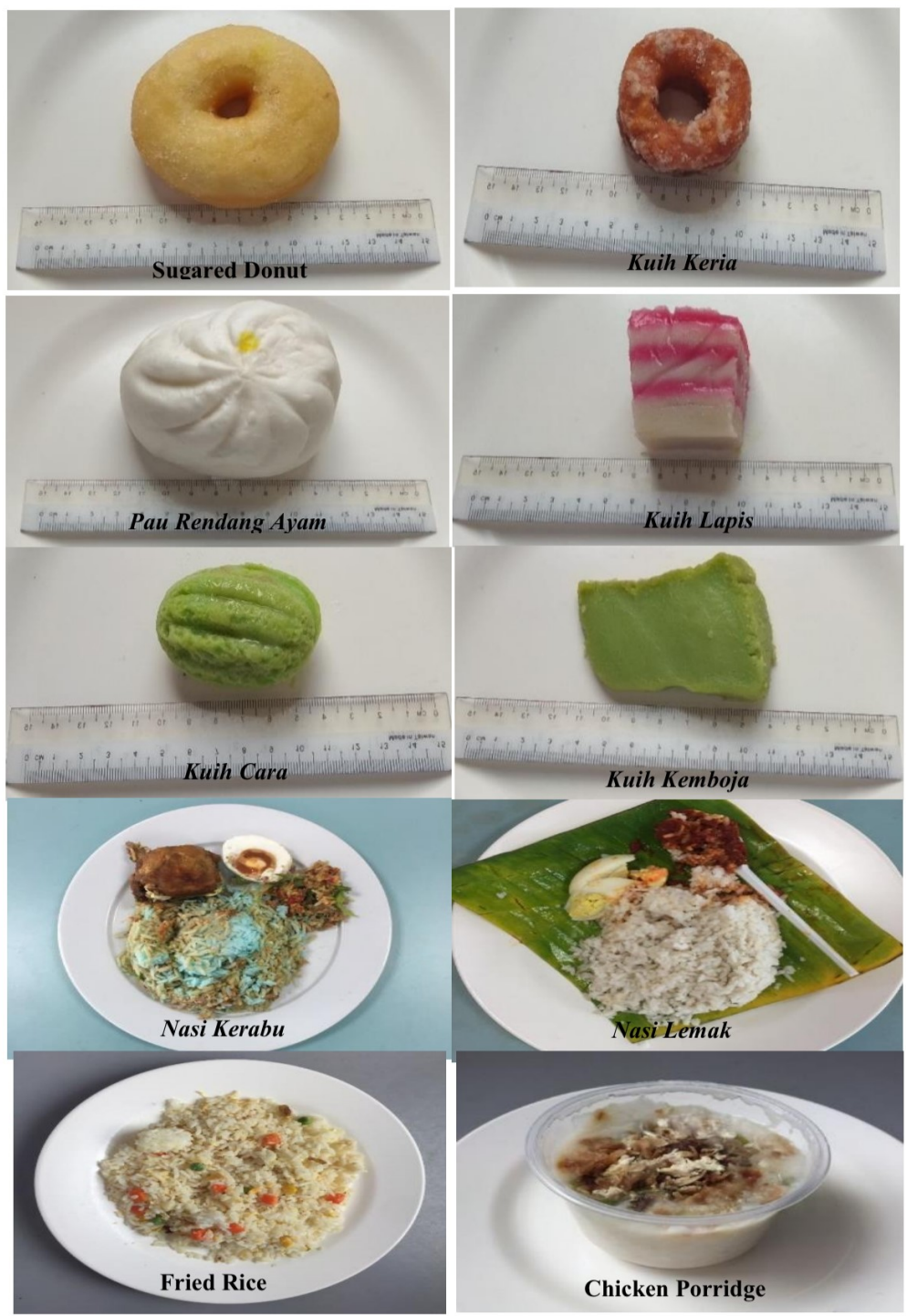

Figure 1. Photograph of actual traditional kuih and rice dishes analysed.

\subsection{Determination of sugar profiles}

High-Performance Liquid Chromatography (HPLC) method was used to determine the sugar composition in each sample by Waters (2012). For the quantification of mixtures of single sugars, a stock solution containing either $100 \mathrm{mg}$ (low standard) or $300 \mathrm{mg}$ (high standard) of each sugar species was prepared in a $100 \mathrm{~mL}$ calibrated volumetric flask. After the transfer of the required sugar quantity, HPLC-grade water was added up to the calibration mark. Dry sample weighing $1.0 \mathrm{~g}$ were added into $50 \mathrm{~mL}$ centrifuge tubes. The acetonitrile mixture $(25 \mathrm{~mL}$ from acetonitrile and water mixture of 50:50) was added and homogenized for 15 mins, and the mixture was centrifuged at $3200 \mathrm{rpm}$ for $30 \mathrm{mins}$. The supernatant was collected and filtered by $0.45 \mu \mathrm{m}$ membrane filter using a syringe. Samples prepared were then kept in a vial before injecting into the HPLC to be analysed.

Total sugar content $(\%)=$ Glucose $(\%)+$ Fructose $(\%)+$ Maltose (\%) + Sucrose (\%) + Lactose (\%)

\subsection{Determination of total available carbohydrate content}

Clegg Anthrone method was used to determine the total available carbohydrate in the samples (AOAC, 2000). The sample was added with $10 \mathrm{~mL}$ water and the solution was stirred using a glass rod to disperse the sample thoroughly. The solution was added with $13 \mathrm{~mL}$ of $52 \%$ perchloric acid and stirred frequently for 20 mins. The content was diluted to $100 \mathrm{~mL}$ with water and filtered into a $250 \mathrm{~mL}$ graduated flask. The cylinder was washed with water and the washing was collected in the same graduated flask. The content was diluted to the mark and mixed thoroughly.

The extracted sample then undergoes the determination process. Approximately $10 \mathrm{~mL}$ of the extracted sample was taken and diluted to $100 \mathrm{~mL}$ with water. Next, $1 \mathrm{~mL}$ of the diluted solution was transferred into a test tube using a pipette. After that, $5 \mathrm{~mL}$ of anthrone reagent was rapidly transferred into all the test tubes, and the content was mixed thoroughly. All the test tube were placed in a boiling water bath for 12 mins and then cooled down to room temperature. Finally, the 
solutions were transferred into glass cuvettes. The absorbance of samples and standards were read at 630 $\mathrm{nm}$ against the blank. The calculation of total available carbohydrate:

Total available carbohydrate content ( $\%$ glucose by weight $)=(25 \times b) /(a \times w)$

Where a: absorbance of glucose standard working solution; b: absorbance of sample extract; and w: the weight of sample taken $(\mathrm{g})$

\subsection{Determination of dialyzable glucose concentration to predict Glycaemic Response (GR)}

Determination of glycaemic index by using in vitro digestion protocol was based from Argyri et al. (2016). The in vitro digestion involved two phases.

In the first phase, a certain amount (the portion that provides $0.25 \mathrm{~g}$ total available carbohydrates) of samples selected and homogenized by using Ultra Turrax T25 with an equal amount of water. Then, the solution of samples incubated with $\alpha$-amylase $(185 \mathrm{U} / \mathrm{g}$ available carbohydrate, $\alpha$-amylase from human saliva, type XIII-A A1031-1KU, Sigma-Aldrich, Taufkirchen, Germany) for 15 mins at $37^{\circ} \mathrm{C}$ shaking incubator ES-20/60 with speed at $110 \mathrm{rpm}$ to imitate the oral digestion. Next, the $\mathrm{pH}$ was adjusted to 2.5 with $0.1 \mathrm{M} \mathrm{HCl}$ and water is added if the volume of the solution is less than $2 \mathrm{~mL}$. Each $2 \mathrm{~mL}$ sample is then transferred into six-well plates. In each well, $0.1 \mathrm{~mL}$ of pepsin (porcine pepsin preparation, suspended in $4 \mathrm{~g} / 100 \mathrm{~mL}$ in $0.1 \mathrm{M} \mathrm{HCl}$, porcine pepsin, P-7000, Sigma-Aldrich, Taufkirchen, Germany) was added and the plates were placed on a shaking incubator at $37^{\circ} \mathrm{C}$ for $2 \mathrm{hrs}$. These will be stimulating the gastric phase in the human digestion. After two hours, a cylindrical insert with a piece of dialysis membrane is placed at the top of each well in such a way that the membrane is in contact with the digest. Then, each ring is filled with $2 \mathrm{~mL}$ 0.1M PIPES buffer $\mathrm{pH}$ 6.5(piperazine1,4-bis(2-ethane-sulfonic acid) disodiumsalt (P3768, Sigma-Aldrich, Taufkirchen, Germany), simulating the gradual increase of $\mathrm{pH}$ in the human small intestine. The plates were incubated for another $30 \mathrm{~min}$, shaking at $37^{\circ}$ C.

The second phase of the in vitro digestion started after the end of this incubation period and lasted for 120 mins. An aliquot $(0.2 \mathrm{~mL})$ taken from the supernatant $(\mathrm{t}$ $=0 \mathrm{~min})$. Subsequently, the insert was carefully removed and $\quad 10 \mu \mathrm{L}$ amyloglucosidase $\quad(3260 \mathrm{U} / \mathrm{mL}$ amyloglucosidase from Aspergillus niger E-AMGDF, Megazyme Inc., Chicago, IL, USA) and $0.5 \mathrm{~mL}$ pancreatin-bile salt mixture $(0.2 \mathrm{~g}$ porcine pancreatin from porcine pancreas, P-1750 Sigma, and $1.2 \mathrm{~g}$ bile extract, B-8631Sigma, suspended in $100 \mathrm{~mL} 0.1 \mathrm{M}$
$\mathrm{NaHCO}_{3}$ ) was added to the well. The cylindrical insert was placed again, and incubation continued in a shaking incubator for 2 hours.

Within $2 \mathrm{hrs}, 0.2 \mathrm{~mL}$ of an aliquot taken out from the dialysate for every 30 mins to determine the glucose $(t=$ 30 mins, $\mathrm{t}=60$ mins, $\mathrm{t}=90$ mins, $\mathrm{t}=120$ mins, where $\mathrm{t}$ $=0$ min was set at the start of the second phase of the in vitro digestion procedure). The digested samples $(0.2 \mathrm{~mL}$ aliquots) was mixed immediately with $0.8 \mathrm{~mL}$ ethanol in a microcentrifuge tube and 30 mins later the tubes were centrifuged for $10 \mathrm{~min}$ at $5000 \mathrm{rpm}$ at $20^{\circ} \mathrm{C}$ to clarify the ethanol supernatant fraction before analysis of sugars. Dialyzable glucose, i.e., the concentration of glucose in the soluble and low molecular weight fraction of the digest, was tested as an index for the prediction of glycaemic response. Glucose determination performs spectrophotometrically using the dinitrosalicylic method (DNS 98\%, 12,884-8, Sigma) in a 96-well plate at $562 \mathrm{~nm}$.

In the in vitro study, glycaemic response ranking of food samples and sugars was considered at 120 mins of dialyzable glucose concentration as the predictor of the ranking. The time selection was based on the highest correlation between dialyzable glucose ratios (in vitro) and blood glucose ratios (in vivo) found at $120 \mathrm{mins}$ (Spearman rho $=0.736, p=0.003$ ) by Argyri et al. (2016). Therefore, 120 mins of dialyzable glucose becomes the index proposed for the prediction of the glycaemic response of food.

\section{Results}

\subsection{Sugar profiles}

Based on Table 1, for all the selected samples of commercial sugars, rice-based meals and traditional kuih and dessert, the highest fructose and glucose content was in palm sugar (fructose $=1.50 \%$, glucose $=2.19 \%$ ), nasi kerabu (fructose $=1.33 \%$, glucose $=1.36 \%$ ) and pau rendang ayam (fructose $=1.81 \%$, glucose $=1.71 \%$ ), respectively. While for the amount of sucrose and total sugar content was highest in icing sugar (sucrose = $99.84 \%$, total sugar $=100 \%$ ), nasi kerabu (sucrose $=$ $4.80 \%$, total sugar $=7.49 \%$ ) and kuih lapis (sucrose $=$ $41.09 \%$, total sugar $=42.20 \%$ ). Maltose was only found in traditional kuih and dessert and highest in kuih keria $(7.16 \%)$.

\subsection{Estimated glycaemic response (dialyzable glucose concentration) at 120 minutes $(\mathrm{mg} / \mathrm{mL})$}

Based on Figure 2, among all the studied sugar samples, sugar in sachet $(3.47 \mathrm{mg} / \mathrm{mL})$ yielded the highest dialyzable glucose concentration followed by palm sugar $(3.19 \mathrm{mg} / \mathrm{mL})$, icing sugar $(3.17 \mathrm{mg} / \mathrm{mL})$, 
Table 1. Sugar content on selected types of commercial sugars, rice-based meals and traditional kuih in Malaysia

\begin{tabular}{|c|c|c|c|c|c|}
\hline Sample & $\begin{array}{l}\text { Fructose } \\
(\% \pm \mathrm{SD})\end{array}$ & $\begin{array}{l}\text { Glucose } \\
(\% \pm \mathrm{SD})\end{array}$ & $\begin{array}{l}\text { Sucrose } \\
(\% \pm \mathrm{SD})\end{array}$ & $\begin{array}{l}\text { Maltose } \\
(\% \pm \mathrm{SD})\end{array}$ & $\begin{array}{c}\text { Total sugar } \\
(\% \pm \mathrm{SD})\end{array}$ \\
\hline \multicolumn{6}{|c|}{ Sugars } \\
\hline Refined sugar & $0.36 \pm 0.02^{\mathrm{e}}$ & $0.29 \pm 0.02^{\mathrm{e}}$ & $96.53 \pm 3.33^{\text {cd }}$ & ND & $97.18 \pm 3.36^{\mathrm{d}}$ \\
\hline Sugar in sachet & $0.37 \pm 0.06^{\mathrm{e}}$ & $0.31 \pm 0.08^{\mathrm{e}}$ & $99.62 \pm 1.92^{\mathrm{bc}}$ & ND & $100.30 \pm 1.78^{\mathrm{cd}}$ \\
\hline Icing sugar & $0.44 \pm 0.05^{\mathrm{d}}$ & $0.37 \pm 0.05^{\mathrm{e}}$ & $99.84 \pm 0.87^{\mathrm{b}}$ & ND & $100.64 \pm 0.77^{\mathrm{c}}$ \\
\hline Sugar with stevia & $0.37 \pm 0.05^{\mathrm{e}}$ & $0.31 \pm 0.05^{\mathrm{e}}$ & $97.73 \pm 1.91^{\mathrm{bcd}}$ & ND & $98.41 \pm 1.81^{\mathrm{cd}}$ \\
\hline Soft brown sugar & $0.81 \pm 0.03^{\mathrm{c}}$ & $0.86 \pm 0.01^{\mathrm{d}}$ & $95.95 \pm 0.16^{\mathrm{d}}$ & ND & $97.63 \pm 0.12^{\mathrm{cd}}$ \\
\hline Aromatic brown sugar & $1.09 \pm 0.02^{\mathrm{b}}$ & $1.26 \pm 0.01^{\mathrm{c}}$ & $96.35 \pm 1.05^{\mathrm{d}}$ & ND & $98.70 \pm 1.02^{\mathrm{cd}}$ \\
\hline Palm sugar & $1.50 \pm 0.01^{\mathrm{a}}$ & $2.19 \pm 0.00^{b}$ & $80.44 \pm 0.09^{\mathrm{e}}$ & ND & $84.14 \pm 0.10^{\mathrm{e}}$ \\
\hline Better brown sugar & ND & ND & $97.31 \pm 0.00^{\mathrm{cd}}$ & ND & $97.31 \pm 0.00^{\mathrm{d}}$ \\
\hline \multicolumn{6}{|c|}{ Rice-based meals } \\
\hline White rice & $0.32 \pm 0.00^{\mathrm{e}}$ & $0.28 \pm 0.01^{\mathrm{e}}$ & $0.08 \pm 0.01^{\mathrm{e}}$ & ND & $0.68 \pm 0.01^{\mathrm{e}}$ \\
\hline Fried Rice & $0.39 \pm 0.02^{\mathrm{e}}$ & $0.39 \pm 0.02^{\mathrm{d}}$ & $0.33 \pm 0.01^{\mathrm{d}}$ & ND & $1.11 \pm 0.00^{\mathrm{d}}$ \\
\hline Nasi Lemak & $0.71 \pm 0.05^{\mathrm{d}}$ & $0.55 \pm 0.01^{\mathrm{c}}$ & $1.96 \pm 0.12^{\mathrm{b}}$ & ND & $3.21 \pm 0.06^{\mathrm{b}}$ \\
\hline Nasi Kerabu & $1.33 \pm 0.01^{\mathrm{c}}$ & $1.36 \pm 0.02^{\mathrm{b}}$ & $4.80 \pm 0.20^{\mathrm{a}}$ & ND & $7.49 \pm 0.17^{\mathrm{a}}$ \\
\hline Chicken porridge & $0.68 \pm 0.05^{\mathrm{d}}$ & $0.73 \pm 0.06^{\mathrm{c}}$ & $1.07 \pm 0.04^{\mathrm{c}}$ & ND & $2.48 \pm 0.06^{\mathrm{c}}$ \\
\hline \multicolumn{6}{|c|}{ Traditional Kuih } \\
\hline Kuih Kemboja & $0.49 \pm 0.04^{\mathrm{d}}$ & $0.46 \pm 0.03^{\mathrm{e}}$ & $34.82 \pm 0.31^{\mathrm{b}}$ & $1.27 \pm 0.01^{\mathrm{c}}$ & $37.05 \pm 0.35^{\mathrm{b}}$ \\
\hline Kuih Cara & $0.39 \pm 0.01^{\mathrm{e}}$ & $0.42 \pm 0.01^{\mathrm{e}}$ & $14.86 \pm 0.27^{\mathrm{d}}$ & $4.84 \pm 0.09^{b}$ & $20.50 \pm 0.42^{\mathrm{d}}$ \\
\hline KuihKeria & $0.76 \pm 0.30^{\mathrm{c}}$ & $0.85 \pm 0.01^{\mathrm{c}}$ & $16.27 \pm 0.31^{\mathrm{c}}$ & $7.16 \pm 0.21^{\mathrm{a}}$ & $25.05 \pm 0.50^{\mathrm{c}}$ \\
\hline Sugared Donut & $0.91 \pm 0.04^{\mathrm{b}}$ & $0.58 \pm 0.01^{\mathrm{d}}$ & $3.35 \pm 0.30^{\mathrm{f}}$ & $0.79 \pm 0.11^{\mathrm{d}}$ & $5.30 \pm 0.00^{\mathrm{f}}$ \\
\hline Pau Rendang Ayam & $1.81 \pm 0.03^{\mathrm{a}}$ & $1.71 \pm 0.03^{b}$ & $12.77 \pm 0.02^{\mathrm{e}}$ & $0.39 \pm 0.00^{\mathrm{e}}$ & $16.65 \pm 0.07^{\mathrm{e}}$ \\
\hline Kuih Lapis & $0.51 \pm 0.02^{\mathrm{d}}$ & $0.61 \pm 0.02^{\mathrm{d}}$ & $41.09 \pm 1.20^{\mathrm{a}}$ & ND & $42.20 \pm 1.27^{\mathrm{a}}$ \\
\hline
\end{tabular}

Values are expressed as mean \pm standard deviation, $n=3$. Values in the same column (same sample type) with same superscript letters were not significantly different ( $\mathrm{p}>0.05$, ANOVA, Duncan). The total sugar is the sum of fructose, glucose and sucrose. ND- Not detected

refined sugar $(1.68 \mathrm{mg} / \mathrm{mL})$, aromatic brown sugar $(1.51$ $\mathrm{mg} / \mathrm{mL})$, soft brown sugar $(1.11 \mathrm{mg} / \mathrm{mL})$, minimal refined brown sugar $(0.66 \mathrm{mg} / \mathrm{mL})$, and sugar with stevia $(0.49 \mathrm{mg} / \mathrm{mL})$.

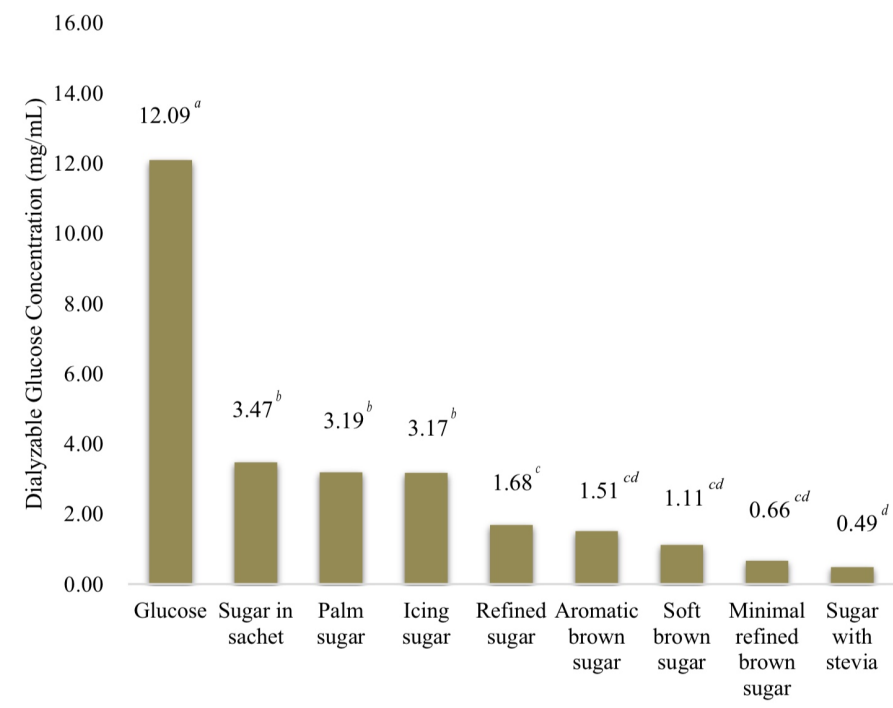

Figure 2. The dialyzable glucose concentration at 120 mins on selected types of sugar samples in descending order. Values are expressed as mean $\pm S D, n=3$. Glucose solution was used as a positive control.

Figure 3 shows among all the studied rice-based meal samples, white rice $(13.23 \mathrm{mg} / \mathrm{mL})$ yielded the highest dialyzable glucose concentration followed by nasi lemak $(13.06 \mathrm{mg} / \mathrm{mL})$, fried rice $(12.94 \mathrm{mg} / \mathrm{mL})$, chicken porridge (12.55 mg/mL), and nasi kerabu (12.33 $\mathrm{mg} / \mathrm{mL}$ ).

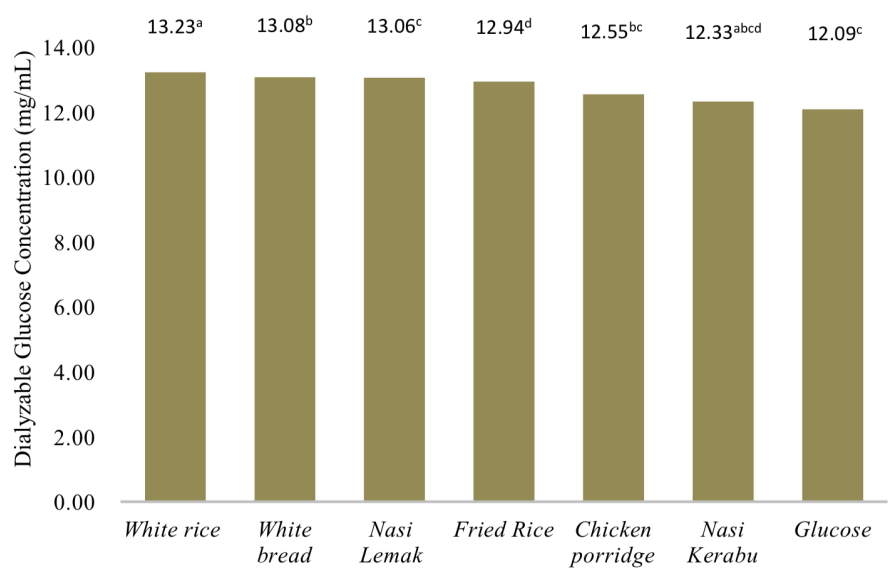

Figure 3. The dialyzable glucose concentration at 120 minutes on selected rice-based meals samples in descending order. Values are expressed as mean $\pm \mathrm{SD}, \mathrm{n}=3$. Glucose solution and white bread are used as a positive control.

While in Figure 4, among all the studied traditional cake and dessert samples, kuih lapis yielded the highest dialyzable glucose concentration $(10.53 \mathrm{mg} / \mathrm{mL})$ followed by kuih kemboja $(10.28 \mathrm{mg} / \mathrm{mL})$, pau rendang ayam $(7.84 \mathrm{mg} / \mathrm{mL})$, kuih cara $(7.02 \mathrm{mg} / \mathrm{mL})$, sugared donut $(6.79 \mathrm{mg} / \mathrm{mL})$, and kuih keria $(6.30 \mathrm{mg} / \mathrm{mL})$. 


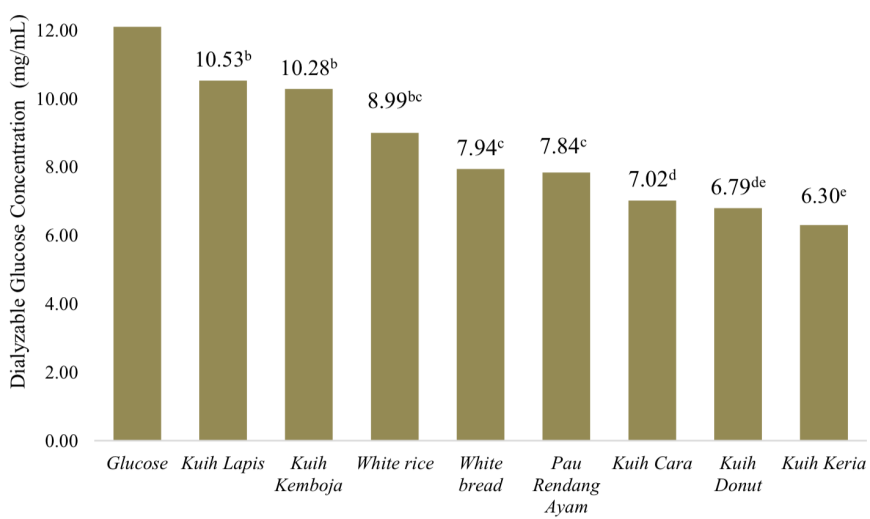

Figure 4 . The dialyzable glucose concentration at 120 minutes on the selected traditional cake and dessert samples in descending order. Values are expressed as mean $\pm \mathrm{SD}, \mathrm{n}=3$. Glucose solution, white bread and white rice were used as the positive control.

\subsection{Correlation of in vitro glycaemic response and sugar composition}

The correlation coefficients of the studied food are presented in Table 2. Sugars showed no correlation between dialyzable glucose concentration at 120 mins and sugar composition. For the selected rice-based meals, there were strong but the inverse correlation between dialyzable glucose concentration at $120 \mathrm{mins}$ and sugar composition $(\mathrm{p}<0.05$ and $\mathrm{p}<0.01)$. While for traditional cake and dessert (kuih), correlation coefficient for sucrose $(r=0.876, p=0.002)$ and total sugar content $(\mathrm{r}=0.775, \mathrm{p}=0.003)$ was strong, significant and positive with glycaemic response at 120 mins.

Table 2. Correlation between dialyzable glucose concentration and sugar composition on the selected food types

\begin{tabular}{|c|c|c|c|}
\hline \multirow[t]{2}{*}{ Food } & \multirow[t]{2}{*}{$\begin{array}{c}\text { Sugar } \\
\text { composition }\end{array}$} & \multicolumn{2}{|c|}{$\begin{array}{c}\text { Dialyzable glucose } \\
\text { concentration } \\
\text { (mg glucose } / 0.25 \text { g CHO of the } \\
\text { sample) } \\
\end{array}$} \\
\hline & & $r$ & $P$ \\
\hline \multirow{4}{*}{ Sugars } & Fructose & 0.143 & \multirow{4}{*}{$p>0.05$} \\
\hline & Glucose & 0.193 & \\
\hline & Sucrose & -0.279 & \\
\hline & Total sugar & -0.258 & \\
\hline \multirow{4}{*}{$\begin{array}{l}\text { Rice-based } \\
\text { meals }\end{array}$} & Fructose & $-0.789 * *$ & 0.007 \\
\hline & Glucose & $-0.866^{* *}$ & 0.001 \\
\hline & Sucrose & $-0.707^{*}$ & 0.022 \\
\hline & Total sugar & $-0.750^{*}$ & 0.012 \\
\hline \multirow{5}{*}{$\begin{array}{c}\text { Traditional } \\
\text { Kuih }\end{array}$} & Fructose & -0.236 & 0.461 \\
\hline & Glucose & -0.167 & 0.603 \\
\hline & Sucrose & $0.876^{*}$ & 0.002 \\
\hline & Maltose & -0.579 & 0.08 \\
\hline & Total sugar & $0.775^{*}$ & 0.003 \\
\hline
\end{tabular}

The correlation was determined by conducted Pearson's Correlation analysis. * Correlation is at $\mathrm{p}<0.05$., ** Correlation is at $\mathrm{p}<0.01$.

\section{Discussion}

In this study, the individual and total sugar (fructose, glucose, sucrose and maltose) and the amount of dialyzable glucose concentration at $120 \mathrm{mins}(\mathrm{mg} / \mathrm{mL})$ based on in vitro method were determined to understand the glycaemic response of food samples as the predictor of ranking. Data obtained from this study may provide a guide to a person wishing to avoid significant glycaemic responses and thereby avoid hyperglycemia. Generally, several factors alter the glycaemic index of food which includes particle size, food structure, level of food processing, cooking technique, the ratio of amylose and amylopectin content and the presence of other macronutrients such as fat and protein (Henry and Thondre, 2011).

Among the studied sugars, sugar with stevia showed the lowest dialyzable glucose concentration at 120 mins as stevia contains bioactive compounds of plants such as alkaloids, flavonoids, tannins and phenolic those can improve the glucose response (Khiraoui and Guedira, 2018). Favourably, among the brown sugars, especially the minimal refined brown sugar also recorded the lowest dialyzable glucose concentration at 120 mins. Previous work comparing concentrations of phenolic constituents in cane sugar manufacturing products reported higher polyphenols in the brown sugars compared to their granulated sugar counterparts (Payet et al., 2016).

According to Edwards et al. (2016), phytochemical compounds such as polyphenols may contribute to the low glycaemic response. Sugars in sachet and icing had similar value, but refined sugar showed significantly lower dialyzable glucose concentration at 120 mins, which point out the effect of gross structure such as grinding and heat treatment in GI and glycaemic response (Arvidsson-lenner et al., 2004). Palm sugar, however, did not show any different from the icing and sugar in a sachet in the dialyzable glucose content. Glucose as the reference food had the highest dialyzable glucose. The glycaemic response trend of glucose and white rice (Figures 2, 3 and 4) were almost similar to Argyri et al. (2016) study, thus indicate the results of this study were acceptable.

Rice and rice-based foods are often classified as having high glycaemic index (GI) (Hsu et al., 2015) and different cooking methods, as well as added ingredients during food preparation, can have a significant effect on the in vitro and in vivo digestibility of rice starch which in turn will affect the glycaemic index and glycaemic response values. Rice is a polysaccharide consisting of long chains of glucose molecules that are linked together either in the form of amylose or amylopectin (Yusof et 
al., 2005). Rice, with high amylose content, exhibited lower glycaemic index values (Kumar et al., 2018). Rice also consists of glucose and sucrose as the primary soluble sugar that gives the sweetness taste to the rice (Bhattacharjee et al., 2002). Commonly, sugar is added into the mixed food to enhance sweetness and palatability. Different types and amounts of sugars are added during the cooking process to enhance the taste of the food (Chong et al., 2019). Generally, the type of food grain, method, and duration of cooking, the amounts of amylose, resistant starch, fibre, and protein content, and amylopectin molecules also could affect the GI values (Kumar et al., 2018).

In this study, nasi kerabu showed the lowest response trend for glucose, which could be due to the presence of a variety of vegetables in the rice. Dietary fibre content was identified as one of the food components that reduced the glycaemic response (Nayak et al., 2014). There was not much difference in the glycaemic response of the different studied rice as all is rice-based meals which contain protein and fat. According to Sun et al. (2014), adding fat and protein to the mixed meals reduced the glycaemic responses by $25 \%$ to $39 \%$ which is consistent with an early report by Welch et al. (1984) as the reduction in GI after adding fat was due to delay in gastric emptying. In healthy subjects, the addition of fat decreased the glycaemic response with a significant reduction in peak rise (Wolever, 2013). Nasi lemak, fried rice, chicken porridge and nasi kerabu are all local delicacies which are very tasty due to the presence of added fat.

Traditional kuih nowadays is convenience food due to its high availability and the easy preparations of some traditional kuih. The preparation of traditional kuih starts from the raw ingredients (sugar and starch), mixing, and heating until the snacks are ready to serve. For example, traditional Malay snacks are chewy desserts made of tapioca flour, sweet potato flour, coconut milk and sugar palm (Sharifah Azizah et al., 2015). There are also different cooking methods used in the preparation of Malay traditional kuih such as frying, steaming, grilling or baking (Raji, Ab Karim, Ishak and Arshad, 2017). The traditional cake and desserts are made from rice flour, and wheat flour has high amylopectin content. According to Arvidsson-lenner et al. (2004), food with amylopectin has a higher glycaemic index value compared to food with amylose.

In this study, kuih lapis has the highest dialyzable glucose concentration compared to other traditional kuih, followed by kuih kemboja, pau rendang ayam, kuih cara, sugared doughnut, and kuih keria. Both, kuih lapi sand kuih kemboja were among the snack with the highest prediction of the glycaemic response as both desserts used rice flour and wheat flour as their main ingredient. The ratio of amylose and amylopectin in foods is one of the factors that could affect the glycaemic response. Rice flour (75-80\% of amylopectin) and wheat flour (75\% of amylopectin), both have high amylopectin content (Chen et al., 2016). According to Arvidsson-lenner et al. (2004), amylopectin caused food to have a higher glycaemic index value compared to amylose. Meanwhile, sugared doughnut showed the lowest dialyzable glucose concentration since margarine (10$20 \%$ of the total ingredient) is one of the main ingredients. Addition of margarine to other foods was expected to lower their glycaemic index, as fat has been shown to flatten and reduce glycaemic responses (Glycaemic Index Foundation, 2017).

Most traditional kuih in Malaysia use sugar as one of their main ingredients to enhance the flavour and appearances. According to Sharifah Azizah et al. (2015), most sweet Kuih such as kuih keria, kuih bingka ubi, kuih kasui, kuih koci, kuih lapis, kuih lopes, kuih ondeonde, kuih sagu, kuih seri muka and kuih talam used granulated sugar in their preparation together with starch sources such as sweet potatoes, rice flour, glutinous flour as well as wheat flour which contributed to the high sugar and available carbohydrate content. The use of the different type of sugar, such as gula melaka however, will slightly reduce the sucrose content. Besides the amount of sugar, gelatinization process of the starch granule which causes by the swelling of the starch granules due to addition of water decreases the starch digestibility causing lower glycaemic response (Parada et al., 2019).

Results of this study have provided an overview of the trend of glycaemic response (not the numerical GI value) of the selected types of commercial sugar, ricebased meals and traditional kuih which can be useful for a future clinical study to estimate the actual GI values. The concentration of dialyzable glucose was used to predict the glycaemic response (Argyri et al., 2016). A similar study needs to be done using in vivo methods to identify the actual values of GI because the validation of in vitro method on glycaemic index value still depends on the in vivo method (Ferrer-Mairal et al., 2012). The actual values of glycaemic index for both in vitro and in vivo methods are needed to ensure more satisfactory and reliable results can be achieved.

\section{Conclusion}

This study showed that for traditional kuih, high sucrose content together with starchy ingredients such as flours (specific amylose and amylopectin ratio) are the 
main factor that affects the in vitro glycaemic response. However, in rice-based meals, the higher the total sugar content, the lower the in vitro glycaemic response which may be due to the presence of other food components such as protein, fat, and fibre in the rice-based meals. For sugar samples, in vitro glycaemic response is influenced by the source of sugar, the degree of processing applied and the presence of polyphenol compounds. Actual glycaemic response and GI of the samples should be determined using in vivo method in the future since this study only gives a ranking overview of the glycaemic response of the selected food samples.

\section{Conflict of Interest}

The authors declare no conflict of interest.

\section{Acknowledgement}

The author would like to acknowledge laboratory staffs at Nutrition laboratory, Faculty of Medicine and Health Sciences, UPM for their help and guidance throughout the research.

\section{References}

Almousa, A., Thomas, M., Siddieg, H., Varghese, S. and Abusnana, S. (2013). The Glycaemic Index of Traditional Types of Bread in UAE. Journal of Nutrition and Food Sciences, 3(3). 1-6. https:// doi.org/10.4172/2155-9600.1000203

Amarra, M.S.V., Khor, G.L. and Chan, P. (2016). Intake of added sugar in Malaysia: A review. Asia Pacific Journal of Clinical Nutrition, 25, 227-240.

AOAC (2000). Association of Official Analytical Chemists. Official Method of Analysis. 13th ed. Washington DC.: AOAC.

Argyri, K., Athanasatou, A., Bouga, M. and Kapsokefalou, M. (2016). The potential of an in vitro digestion method for predicting glycaemic response of foods and meals. Nutrients, 8(4). 4-10. https:// doi.org/10.3390/nu8040209

Arvidsson-lenner, R., Asp, N., Axelsen, M., Bryngelsson, S., Haapa, E., Ja, A. and Vessby, B. (2004). Glycaemic Index, 1981(2), 84-94. https:// doi.org/10.1080/11026480410033999

Augustin, L.S.A., Kendall, C.W.C., Jenkins, D.J.A., Willett, W.C., Astrup, A., Barclay, A.W., Björck, J.C., Brand-Miller, Brighenti, F., Buyken, A.E., Ceriello, A., La Vecchia, C., Livesey, G., Liu, S., Riccardi, G., Rizkalla, S.W., Sievenpiper, J.L., Trichopoulou, A., Wolever, T.M.S., Baer-Sinnott, S. and Poli, A. (2015). Glycaemic index, glycaemic load and glycaemic response: An International
Scientific Consensus Summit from the International Carbohydrate Quality Consortium (ICQC). Nutrition, Metabolism and Cardiovascular Diseases, 25(9), 795-815. https://doi.org/10.1016/ j.numecd.2015.05.005

Bhattacharjee, P., Singhal, R.S. and Kulkarni, P.R. (2002). Basmati Rice: A Review. International Journal of Food Science and Technology, 37, 1-12. https://doi.org/10.1046/j.1365-2621.2002.00541.x

Chen, G., Zhou, J., Liu, Y., Lu, X. and Han, C. (2016). Biosynthesis and Regulation of Wheat Amylose and Amylopectin from Proteomic and Phosphoproteomic Characterization of Granule- binding Proteins. Scientific Reports, 6, $3311 \mathrm{https} / / /$ doi.org/10.1038/ srep33111

Chong, C.P., Hasnah, H., Suzana, S. and Md Noh, M.F. (2019). Individual sugars contents in cooked dishes, processed foods, fruits and beverages commonly consumed by Malaysian. Journal of Food Composition and Analysis, 80, 1-9. https:// doi.org/10.1016/j.jfca.2019.03.017

Edwards, C.H., Rossi, M., Corpe, C.P., Butterworth, P.J. and Ellis, P.R. (2016). The role of sugars and sweeteners in food, diet and health: Alternatives for the future. Trends in Food Science and Technology, $56,158-166$. https://doi.org/10.1016/ j.tifs.2016.07.008

Englyst, K.N., Englyst, H.N., Hudson, G.J., Cole, T.J. and Cummings, J.H. (1999). Rapidly available glucose in foods: An in vitro measurement that reflects the glycaemic response. American Journal of Clinical Nutrition, 69, 448-454. https:// doi.org/10.1093/ajen/69.3.448

Ferrer-Mairal, A., Peñalva-Lapuente, C., Iglesia, I., Urtasun, L., De Miguel-Etayo, P., Remón, S., Cortés, E. and Moreno, L.A. (2012). In vitro and in vivo assessment of the glycemic index of bakery products: influence of the reformulation of ingredients. European Journal of Nutrition, 51, 947954. https://doi.org/10.1007/s00394-011-0272-6

Glycaemic Index Foundation. (2017). What affects the GI value? Retrieved from The Glycemic website: https://www.gisymbol.com/what-affects-the-givalue/

Henry, C.J.K. and Thondre, P.S. (2011). The glycemic index: Concept, recent developments and its impact on diabetes and obesity. In Paseternak, C. (Ed.) Access Not Excess., p. 154-175. London, UK: Smith -Gordon.

Hsu, R.J. C., Lu, S., Chang, Y.H. and Chiang, W. (2015). Effects of added water and retrogradation on starch digestibility of cooked rice flours with 
different amylose content. Journal of Cereal Science, 61, 1-7. https://doi.org/10.1016/ j.jcs.2014.03.002

Jenkins, A.L. (2007). The glycemic index: Looking back 25 years. Cereal Foods World, 52, 50-53. https:// doi.org/10.1094/CFW-52-1-0050

Khiraoui, A. and Guedira, T. (2018). Effect of Stevia rebaudiana, sucrose and aspartame on human health: A comprehensive review. Journal of Medicinal Plants, 6(1), 102-108.

Kumar, A., Sahoo, S., Sahu, S., Nayak, L., Ngangkham, U., Parameswaran, C., Bose, L.K., Samantaray, S., Kumar, G. and Sharma, S.G. (2018). Rice with pulses or cooking oils can be used to elicit lower glycaemic response. Journal of Food Composition and Analysis, 71, 1-7. https://doi.org/10.1016/ j.jfca.2018.05.003

Nayak, B., Berrios, J.D.J. and Tang, J. (2014). Impact of food processing on the glycaemic index (GI) of potato products. Food Research International, 56, 35 -46. https://doi.org/10.1016/j.foodres.2013.12.020

Norimah, A.K., Safiah, M., Jamal, K., Siti Haslinda, Zuhaida, H., Rohida, S., Fatimah, S., Norazlin, S., Poh, B.K., Kandiah, M., Zalilah, M.S., Wan Manan, W.M., Fatimah, S. and Azmi, M.Y. (2008). Food Consumption Patterns: Findings from the Malaysian Adult Nutrition Survey (MANS). Malaysian Journal of Nutrition, 14(1), 25-39.

Nur Indrawaty, L., Khor, G.L. and Imelda, A.A. (2012). Food Consumption Patterns and Nutrition Transition in South East Asia. Public Health Nutrition Journal, 16(9), 1637-1643. https://doi.org/10.1017/ S1368980012004569

Parada, J., Pérez-Correa, J.R. and Pérez-Jiménez, J. (2019). Design of low glycaemic response foods using polyphenols from seaweed. Journal of Functional Foods, 56, 33-39. https:// doi.org/10.1016/j.jff.2019.03.004

Payet, B., Cheong Sing, A.S. and Smadja. J. (2006). Comparison of the concentrations of phenolic constituents in cane sugar manufacturing products with their antioxidant activities. Journal of Agriculture and Food Chemistry, 54(19), 7270-7276. https://doi.org/10.1021/jf060808o

Sharifah Azizah, T.N., Nik Shanita, S. and Hasnah, H. (2015). Amount and types of sugars in selected commercial and traditional kuih in Klang Valley, Malaysia. International Food Research Journal, 22 (6), 2642-2649.

Sun, L.J., Ranawana, D.V., Leow, M.K.S. and Henry, C.J. (2014). Effect of chicken, fat, and vegetable on glycaemia and insulinaemia to a white rice-based meal in healthy adults. European Journal of Nutrition, 53(8), 1719-1726. https://doi.org/10.1007/ s00394-014-0678-z

Sun, L., Lee, D.E.M., Tan, W.J.K., Ranawana, D.V., Quek, Y.C.R., Goh, H.J. and Henry, C.J. (2015). Glycaemic index and glycaemic load of selected popular foods consumed in Southeast Asia. British Journal of Nutrition, 113(5), 843-848. https:// doi.org/10.1017/S0007114514004425

Welch, I.M., Bruce, C., Hill, S.E. and Read, N.W. (1984). Duodenal and lleallipid suppresses postprandial blood glucose and insulin responses in man: Possible implications for the dietary management of diabetes mellitus. Clinical Science, 72(2), 209-16. https://doi.org/10.1017/ S0007114514004425

Wolever, T.M.S. (2013). Is glycaemic index (GI) a valid measure of carbohydrate quality? European Journal of Clinical Nutrition, 67(5), 522-531. https:// doi.org/10.1038/ejen.2013.27

World Health Organization (WHO). (2015). Sugars intake for adults and children. Retrieved from WHO website: https://www.who.int/nutrition/publications/ guidelines/sugars_intake/en/

Yusof, B.N.M., Talib, R.A. and Karim, N.A. (2005). Glycaemic Index of Eight Types of Commercial Rice in Malaysia. Malaysian Journal of Nutrition, 11 (2), 151-163. 